Document downloaded from:

http://hdl.handle.net/10251/65198

This paper must be cited as:

Bermúdez Tamarit, VR.; Lujan Martinez, JM.; Ruiz Rosales, S.; Campos, D.; Linares Rodríguez, WG. (2015). New European Driving Cycle assessment by means of particle size distributions in a light-duty diesel engine fuelled with different fuel formulations. Fuel. 140:649-659. doi:10.1016/j.fuel.2014.10.016.

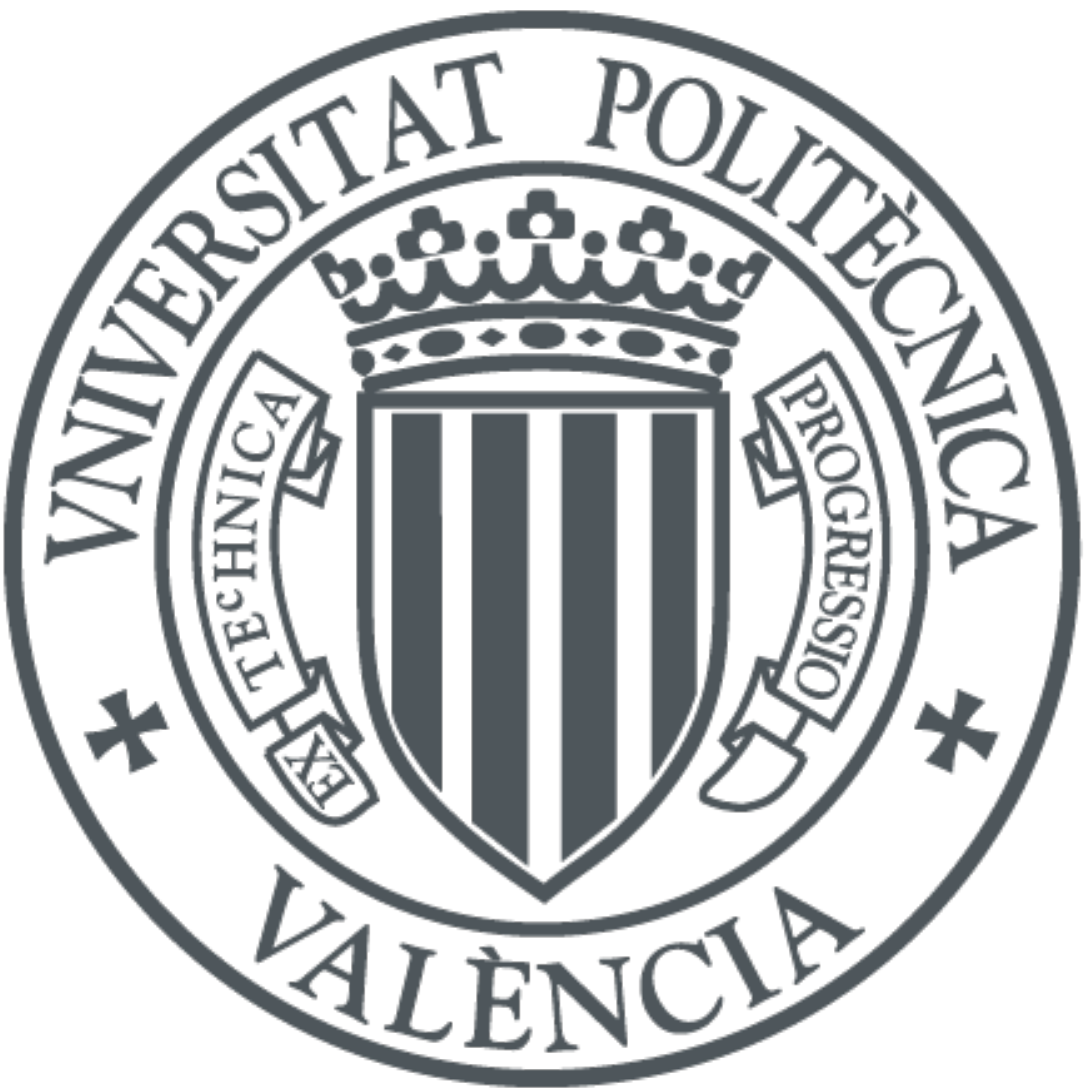

The final publication is available at

http://dx.doi.org/10.1016/j.fuel.2014.10.016

Copyright Elsevier

Additional Information 


\title{
New European Driving Cycle assessment by means of particle size distributions in a light-duty diesel engine fuelled with different fuel formulations
}

\author{
Vicente Bermúdez ${ }^{\mathrm{a}, *}$, José Manuel Lujána ${ }^{\mathrm{a}}$, Santiago Ruiz ${ }^{\mathrm{a}}$, Daniel Campos ${ }^{\mathrm{a}}$, Waldemar G. Linares ${ }^{\mathrm{b}}$ \\ ${ }^{a}$ Universitat Politècnica de València, CMT-Motores Térmicos, Camino de Vera s/n, 46022 Valencia, Spain. \\ ${ }^{b}$ AVL List GmbH, Hans-List-Platz 1, 8020 Graz, Austria
}

\begin{abstract}
In this study, an experimental investigation of particle size distribution emission over performance of transient conditions in a high speed diesel engine fuelled with diesel, biodiesel and Fischer Tropsch fuels have been assessed. Six fuels with different properties have been tested in a 4-cylinder light-duty diesel engine typically used for European passenger cars. The cycle used in this study was the New European Driving Cycle (NEDC) and each test was carried out after a stabilization warming period in order to avoid cold start effects. A comparative analysis between nucleation and accumulation particle mode concentration, particle size distributions and a geometric mean diameter calculation are presented in this paper. In this sense, a reduction in the range of particle diameter emitted and a decrease in accumulation particle mode concentration with Fischer Tropsch fuel during the EUDC were found. In contrast, all biofuels used show an increase of particle number concentration in nucleation-mode during the urban cycles (ECE-15) related to combustion damage at low load conditions. Finally, an increase in the sulfur content diesel fuel leads to an increase in the geometric mean diameter of particle size distribution related to the increase in accumulation particle concentration during the entire cycle.
\end{abstract}

Keywords: Dynamic cycle, Biofuels, Fischer Tropsch, Particle emission, Geometric mean diameter

\section{Introduction}

The major source of air pollution comes from vehicles powered by combustion engines using fossil fuels [1]. This 3 type of vehicles are commonly used for road, rail or sea transport, being diesel engines the most popular ones mounted on these vehicles [2].

Over the last decades, diesel engines have been increasing their sales sharply in world market [3]. In this sense, this 6 is the most widely used engine type in the European Union due to the fact that it has lower specific fuel consumption 7 than its gasoline counterparts [4]. Conversely, diesel engines exhibit both high particles and high nitrogen oxides 8 emission due to the high injection pressures that are already developing and the high air-to-fuel ratio which is obtained 9 during the combustion process [5]. Thus, the particle emission problem associated to this engine type has become very

\footnotetext{
*V. Bermúdez. CMT-Motores Térmicos, Universitat Politècnica de València, Camino de Vera s/n, 46022 Valencia, Spain. Phone: +34 963877650 Fax: +34 963877659 e-mail: bermudez@ mot.upv.es 
important because the morphology of these particles cause serious toxicological and environmental problems [6, 7], such as asthma or cardiorespiratory diseases. These problems are caused by the fact that emitted particle diameters have been getting smaller; being these types of nanoparticles the most harmful to the airways [8].

Concerning these health problems, during the last years, the European Union has been increasing the reduction on particle emission limits. At first glance, soot mass emitted was limited [9] in order to more recently incorporate a limit on the number of particles that are expelled into the atmosphere [10]. For this purpose, a growing interest of the scientific community in order to research methods or alternatives to reduce the particulate emissions by incorporating particulate filters [11, 12], improvements in the combustion process [13], exploring injection parameters [14], optimization of combustion chamber geometry [15] or varying the position of aftertreatment systems [16] have been showed in a recent years.

Another attracting area increasing the scientific interest is the use of biofuels or alternative fuels [17] as a substitute of fossil fuels, being biodiesel widely used as alternative fuel for internal combustion engines [18]. This is due to its advantages, especially environmental improvements $[19,20]$. Biodiesel fuels are known to reduce engine exhaust emissions [21], being the reduction in gaseous emission confirmed by diverse authors [22-24] so it appears as a good sustainable alternative to the depletion of fossil stocks. Its main advantage is that they are environmentally friendly fuels and have a $100 \%$ pure renewable origin [25].

As an alternative to biodiesel, other fuels currently used in diesel engines are synthetic oils obtained through Fischer Tropsch process [26], which are considered as an interesting substitute of diesel fuel. Fischer Tropsch process is a chemical process for the production of liquid hydrocarbons from synthesis gas (GTL) $\left(\mathrm{CO}\right.$ and $\left.\mathrm{H}_{2}\right)[27,28]$ when natural gas is the raw material. The absence of aromatic compounds favours reduction of particle matter and NOx formation due to the high cetane number related to paraffinic structure [29], which would improve the NOx-PM trade off in diesel engines [30].

Although a number of works have assessed the effect of fuel formulation on gaseous emission in transient conditions, but not on determining the influence of fuel formulation on particle size distributions [31]. Moreover, the few published studies concerning particle size distribution have been primarily based on the evaluation of the effects of fuel formulation during stationary operating conditions [32], being certain published works [33, 34] centered in particle emission analysis but just refered on the evaluation of total particles emitted.

This paper is presented in order to explore the effect of fuel formulation on the particle size distribution during transient operating conditions. Six alternative fuels were tested in a diesel engine stablishing the difference on particle emission when dynamic conditions are applied. In this sense, the objective of this paper is to make an exploration of the effects of different fuels formulation in terms of particle size distribution (PSD) and particle emission during the assessment of New European Driving Cycle (NEDC). 


\section{Material and methods}

\subsection{Experimental Setup}

This study was performed in a 2-liter, 4-cylinder, high-speed direct injection diesel engine (HSDI) for passenger car applications. The engine was equiped with a high-pressure loop exhaust gas recirculation system (HP-EGR) and a high-pressure fuel injection pump using a common-rail injection systeme. The main engine characteristics are given in Table 1. For all experimental test, original fuel injection, turbocharging and exhaust gas recirculation strategies were applied in the entire range of engine performance.

The engine was connected to an AC dynamometric brake, which allows instant engine speed and torque control until $250 \mathrm{~kW}$. For engine operation, the Engine Control Unit (ECU) was fully accessible and it could be operated through the ETAS-INCA software being the engine fully equipped with $\mathrm{K}$ thermocouples and pressure sensors in the exhaust, cooling, intake and lubrication systems.

In order to obtain accurate measurement, fuel consumption was determined by two methods. Firstly, a gravimetric system AVL-733S Dynamic Fuel Meter was used. Since the response time of AVL-733S was too long for transient operation, fuel consumption signal provided by the ECU was calibrated in steady state operating conditions, and then used as a second fuel consumption measuring system [35]. For air mass flow rate measurement at the intake manifold, a Sensyflow-P Sensycon hot-plate anemometer system was used.

For particle emission measurement, a TSI-Engine Exhaust Particle Sizer (EEPS) spectrometer was used in order to obtain fast response in particle size distribution measurements during dynamic cycles [36]. EEPS is capable to measure particle size distribution at a sample-rate of up to $1 \mathrm{~Hz}$ providing a measurement range between 5.6 to 560 $\mathrm{nm}$. The measurements were taken downstream the diesel oxidation catalyst (DOC) and before the diesel particulate filter (DPF). Figure 1 shows the experimental setup designed for this study.

\subsection{Fuels properties}

The six fuels studied in this work are described below and further details on their characterization are given in Table 2. These fuels have been supplied by different private companies. On the one hand, pure diesel fuels are from the Spanish company Repsol S.A., being the French company Novance the supplier for all biodiesel fuels. On the other hand, South African company Sasol Technology Ltd. has been responsible for providing the Fischer Tropsch fuel. The characterization of the two pure diesel fuels, three biofuels and the sintetic fuel used were obtained in a certified laboratory according to the UNE-EN 590 for diesel fuel and to the UNE-EN 14214 for the alternative fuels.

- As a reference to compare the different results obtained in the study, an ultra-low sulfur diesel fuel (ULSD) with less than $10 \mathrm{ppm}(\mathrm{D} .7 \mathrm{ppm})$ sulfur content was used. Additionally, a diesel fuel with low sulfur content (LSD) less than $50 \mathrm{ppm}(D .50 \mathrm{ppm})$ sulfur content also has been used. Actual regulation (UNE-EN 590) establishes that certain amount of biodiesel should be included in the commercial diesel ( $<7 \%$ Vol. content), but $D .7 p p m$ and D.50ppm were explicitly ordered and supplied with any other biodiesel content for this study. Since the 
purpose of this work is to evaluate particle size distribution with the use of different fuel formulations, the biodiesel content was removed from diesel in order to remove its influence on particles emitted.

- The different biofuels used in this work were obtained by transesterification of palm oil $(B P)$, soybean oil $(B S)$, and rapeseed oil $(B R)$. Through this process (transesterification), glycerol and esters are obtained by triglycerides (vegetable oil) and alcohol in a catalyst presence.

- Finally, a Fischer Tropsch fuel $(F T)$ produced through gas-to-liquid process was also used.

\subsection{Particle measurement method}

The methodology used to sample the exhaust aerosol from tailpipe and to measure particle size distribution in transient conditions was performed in the test bench according to Desantes et al. [37], as shown in Figure 2.

The dilution system used for this study was a DekatißFine Particle Sampler FPS-4000 [38]. This system dilutes the sample in two stages. A porous tube (PTD) is used as the primary diluter, and subsequently an ejector diluter (ED) carries out the secondary dilution, as shown Figure 2 from $\mathrm{A} \rightarrow \mathrm{B}$ and $\mathrm{B} \rightarrow \mathrm{C}$ ways. The particles within the size range of $10-50 \mathrm{~nm}$ are very unstable and are significantly affected by the dilution temperature due to the fact that they consist of a solid core that contains some volatile fractions.

In this sense, the dilution ratio affects gas-to-particle conversion phenomena through the nucleation and adsorption of the soluble organic fractions (SOF) on the soot [39] or the supersaturate vapor condensation [40]. Applying this methodology, smaller particle diameters are stabilized avoiding homogeneous and heterogeneous nucleation [41].

\subsection{Test procedure}

Actual European regulation [42], establishes that New European Driving Cycle (NEDC) test should begin with the engine temperature within the range $20{ }^{\circ} \mathrm{Cto} 35{ }^{\circ} \mathrm{Cwhen}$ the test is performed to evaluate regulated pollutant emission. This procedure taking into account cold start (first combustion cycles at low temperature coolant) and DOC light-off activation (major part of pollutants emitted are enclosed during the first urban cycle at cold start conditions) or aftertreatment efficiency.

However, the objective for this study is to evaluate particle size distribution for each fuel formulation, evaluating only the influence of fuel used and to establish the quantity of particles emitted during a homologation cycle, but just not to homologation purpose. In this sense, particle measurements were carried out at DPF inlet in order to remove the influence of DPF efficiency. Furthermore, the engine used in this work is a EURO 4 calibration, which has not implemented an engine calibration in order to reduce particle number emission, like EURO 6 engines (which establishes $6 \times 10^{11} \# / \mathrm{km}$ particle limit).

Due to these reasons, a modification was made when NEDC were performed, warming up the engine before the performance of the cycle. The process was done running the engine at $1500 \mathrm{~min}^{-1}$ and $25 \%$ of engine load (90 $\mathrm{Nm}$ ). The criterion for engine thermal stabilization was the DPF outlet temperature (reached after 9 minutes of engine 
running), which is the last temperature measured in the exhaust line. For each fuel, this test procedure was realized before the NEDC assessment. In this sense, all tests were done at the same conditions showing Figure 3 an example of the test procedure carried out for each fuel formulation.

\subsection{Calculation methods}

In order to obtain good accuracy in the decomposition of accumulation-mode and nucleation-mode particle concentrations, particle size distributions can be decomposed by equation (1) according to [43]. It establishes that total particle size distribution is the sum of both particle mode concentrations, assuming the log-normal size distribution function:

$$
\begin{aligned}
\frac{d N_{i}}{d \log d p_{i}} & =\frac{1-x}{\sqrt{2 \pi} \log \sigma_{g 1}} \exp \left[-\frac{\log ^{2}\left(\frac{d p_{1}}{d p_{g 1}}\right)}{2 \log ^{2} \sigma_{g 1}}\right]+ \\
& +\frac{x}{\sqrt{2 \pi} \log \sigma_{g 2}} \exp \left[-\frac{\log ^{2}\left(\frac{d p_{2}}{d p_{g 2}}\right)}{2 \log ^{2} \sigma_{g 2}}\right]
\end{aligned}
$$

In Equation (1), $x$ is the ratio of the total concentrations number of two distributions, $d p_{1}, d p_{2}, \sigma_{g 1}$ and $\sigma_{g 2}$ are the geometric mean diameters and geometric standard deviations of each peak, and $N_{i}$ is the particle number concentration of particle size $d p_{i}$. The fit was achieved by minimizing the mean square error function by means of the Nelder-Mead simplex method.

Several studies proposed nucleation mode limits between 30 and $50 \mathrm{~nm}$ [44]. In this case, the nucleation-mode particle concentration was decomposed from 5.6 to $30 \mathrm{~nm}$, being the accumulation-mode particle concentration ranged from 30 to $560 \mathrm{~nm}$. To calculate total particle number (PN) concentration and geometric mean diameter (GMD), equations 2 and 3 were used respectively:

$$
\begin{array}{r}
d N=\sum_{d p(\text { lower })}^{d p(\text { upper })} d N_{i} \\
G M D=\frac{\sum_{d p(\text { lower })}^{d p \text { upper })} d N_{i} \ln d p_{i}}{d N}
\end{array}
$$

When transient particle emission measurement is carried out, there are relevant difficulties associated with the particle measurement that need to be taken into account when transient tests are being performed. The problem is that particle analyzer usually has a longer response time than the rest of the measurement systems installed. Therefore, particle emission measurement are slightly delayed in comparison with the rest of engine parameters. Since analyzers measure particle concentration, the exhaust mass flow must be determined to calculate the instantaneous and accumulated number of particles emitted during the whole cycle. Therefore, the synchronization between the exhaust mass 
flow and the particle concentration measurement devices becomes critical. The synchronizing method used in this work is widely described by Broatch et al. [45].

Due to the fact that the study was focused on particle emission analysis comparison, a normalization between the different particle emission levels produced with the six fuel used became necesary. In this regard, in order to stablish a quantification differences, a "total particle-energy ratio" (TDER) has been calculated for each fuel formulation used. The normalization of particles emitted with fuel consumption and lower heating value (LHV) was carried out according to equation 4 .

$$
T P E R=\frac{\text { Particles }_{\text {emitted }}}{\text { Energy }_{\text {consumed }}}=\frac{\text { Particle }_{\text {emitted }}}{\text { Fuel }_{\text {consumed }} \cdot \text { LHV }}
$$

The reason for including this type of index lies in the difference in fuel consumption for each fuel (due to LHV, stoichiometric air-fuel ratio and oxygen content) and it could produce a deviation in the analysis of total particles emitted. In this sense, this index provides a normalization of the particles emitted taking into account the fuel consumed for the assessment of NEDC and the different fuel formulation properties.

\section{Test results and discussion}

In this section, a detailed description of the results found during the assessment of NEDC with different fuel formulations is presented. A brief engine performance explanation, a detailed particle emission evaluation, a particle size distribution analysis and a geometric mean diameters calculation are included in the next subsections.

\subsection{Engine performance}

Although the purpose of this work is not to evaluate the use of different fuel formulations in terms of engine performance, the control of some parameters such as fuel consumption and the fresh air mass flow rate is needed in order to improve particle emission analysis.

Figure 4 shows fuel consumption during the NEDC with different fuel formulations. The graph also includes two zooms made at the end of NEDC, and at the end of the first urban driving cycle (ECE-15).

As shown in Zoom A of Figure 4, at the end of the first urban cycle is possible to observe some differences in fuel consumption. On one hand, when the FT fuel is used, it presents the lowest fuel consumption. The reason lies in a different fuel formulation. For $F T$ fuel, $\mathrm{H} / \mathrm{C}$ ratio exceeds the reference $D .7 p p m$ fuel (2.12 vs. 1.86) so its lower heating value is slightly higher $(43.7 \mathrm{MJ} / \mathrm{kg}$ vs. $42.9 \mathrm{MJ} / \mathrm{kg})$. As a consequence, fuel consumption was improved during the first ECE-15. On the other hand, fuel consumption regarding $B S, B P$ and $B R$ fuels is increased because their heating value are lower.

Regarding the extra urban driving cycle (EUDC), a sharply increase in fuel consumption for all fuel formulations occurs during the last part of EUDC. The trend shown on fuel consumption during the first ECE-15 is maintained at the end of NEDC (Zoom B of Figure 4). Otherwise, for the whole NEDC a clear difference is depicted, reaching 
higher values in fuel consumption for the three biodiesel fuels above D.7ppm, D.50ppm and FT fuels. These sharply increase in fuel consumptions during this section is related to the way in which the engine map reaches the specified velocity. Since this value is reached by means of engine speed and engine load, higher loads produce a higher variation in fuel consumption (for a given engine speed and load, lesser lower heating values, increased fuel consumption).

Figure 5 shows fresh air mass flow rate entering into the intake manifold during the NEDC assessment when different fuel formulations were used. Concerning the three biofuels, and focusing on areas where the velocity is constant, it is observed that the air mass flow rate is lower than in the case of D.7ppm fuel. This is due to the fact that the stoichiometric air-to-fuel ratio (AFR) is less than D.7ppm fuel, so that the amount of required air for complete combustion in the case of the three biofuels is less. It is also due to the oxygen content, since biofuels have a higher content than diesel fuel (Table 2) which implies a higher brake thermal efficiency at the same air mass flow conditions. In contrast, in the case of $F T$ fuel, the quantity of air demanded is higher since its stoichiometric ratio is higher.

These statements are confirmed by Plot B in Figure 5. This plot points out the difference in air-to-fuel ratio measured during the assessment of each NEDC, being the FT fuel which presents the highest values of AFR during the constant velocity phases. For the case of biofuels, it is also confirmed that AFR is lower than D.7ppm fuel. It is interesting for particle emission analysis since higher air mass flow rate implies higher exhaust mass flow rate and it could produce higher particle emission.

It should be noted that air mass flow rate demanded by the engine has been calibrated according to a reference diesel (similar to $D .7 p p m$ fuel) regardless of fuel consumption. Therefore, a recalibration of air mass flow rate would require a new air mass flow rate maps optimization.

\subsection{Particle emission analysis.}

A detailed analysis of particle emission has been carried out separating nucleation-mode, accumulation-mode, and total particle concentration during the NEDC. The analysis is divided in three phases. Firstly, the analysis was focused on total particle emission. After total particle emission was analyzed during the ECE-15 (four ECE-15 cycles average) and EUDC, the accumulation-mode particle concentration is evaluated. Finally, nucleation-mode particle concentration is studied. In this sense, Figure 6 shows plots where different particle concentration are analyzed.

At first glance, as shown in Figure 6.A during the urban phase, it can be say that particle emission pattern vary with different fuels formulations. The main difference can be observed during idle phases, in which $B R, B S$ and $B P$ fuels show higher particle emission than D.7ppm, D.50ppm and FT fuels. In contrast, a relative maximums of total particle concentration occurs during gear changes as the demanded velocity increases.

When the analysis is focused on EUDC (Figure 6.B), total particle concentration is increased when comparing to the ECE-15 (concentration peaks around $1 \cdot 10^{14} \# / \mathrm{m}^{3}$ vs. $8 \cdot 10^{13} \# / \mathrm{m}^{3}$ ). On one hand, as in the ECE-15, a relative maximums of total particle concentration occurs during gear changes, regardless of the fuel used. On the other hand, an absolute maximum of total particle emission occurs during the acceleration ramp from 100 to $120 \mathrm{~km} / \mathrm{h}$ (increasing load demand). Remarkably, the fuel presenting highest total particle emission during this phase is D.50ppm. 
Due to the fact that particle size distributions emitted by diesel engines usually have a mode diameter centered on accumulation-mode particle concentration [46], nucleation-mode particle concentration is generally lower in comparison. Thus, over $70 \%$ of total particle emitted belong to accumulation mode particle concentration. As shown in Figure 6.C, accumulation-mode particle concentration in the ECE-15 is very similar for all the fuels used, except $B R$ fuel, which has slighty higher accumulation-mode particle emission than any other fuel.

In contrast, Figure 6.D clearly shows difference in accumulation-mode particle concentration. During the last part of EUDC an increase in this particles type occurs. It is due to the power demand required by the engine, so both injection pressure and injected fuel amount increase, and therefore accumulation-mode particle emission increases. As mentioned, D.50ppm fuel presents the highest particle emission during this phase. The high sulfur content in this fuel helps to form new accumulation-mode particles as a nucleation-mode precursor. On one hand, when the sulfur content is insignificant as in $D .7 p p m$ fuel, a reduction in the accumulation-mode particle concentration can be depicted. On the other hand, accumulation-mode particle concentration is smaller if biofuels $(B P, B R$ and $B S)$ and $F T$ fuel are compared with the reference D.7ppm fuel.

Finally, when the analysis focuses on nucleation-mode particle concentration during the ECE-15 section, a quite low emission is observed when comparing to accumulation-mode particle concentration, as shown Figure 6.E. For this particles type, minimum concentrations occur during the deceleration ramps due to the absence of fuel injected. Regarding nucleation-mode particle concentration produced with different fuel formulations, a similiar emission level for all fuels in the urban cycle can be set, except to $B R$ fuel. Only a small difference in nucleation-mode particle concentration can be seen during the sections where load begins to increase. In this sense, D.7ppm fuel presents the lowest emission, followed by $D .50 \mathrm{ppm}$ fuel. In contrast, biofuels and $F T$ fuel have a higher emission level for these particles type.

When velocity demand increases and nucleation-mode particle concentration analysis is focused on EUDC, differences become more pronounced between different fuels. The minimum emission level of this particles type is shown with reference diesel $(D .7 p p m)$. In the same way, D.50ppm fuel presents a similar reference diesel emission, slightly over it. However, with the biofuels use, an increase in these particles type has been observed, being $B R$ fuel the greatest nucleation-mode particle concentration emmiter respect to reference $D .7 p p m$ fuel. Finally, it can be stated that nucleation-mode particle concentration does not increase with the use of $F T$ fuel.

Given the above, Figure 7 depicts total particles number emitted by the different fuels used during the NEDC. In this way, it can be seen that the highest level of particle emitted is due to D.50ppm fuel. This fuel presents an increase around $15 \%$ than D.7ppm fuel $\left(9.56 \cdot 10^{14} \#\right.$ vs. $\left.8.3 \cdot 10^{14} \#\right)$. It is remarcable since the only difference between these fuels is due to sulphur content. This fact, in addition to the previous results on air mass flow rate (as explained in Section 3.1) yields in an increase in total particles emitted.

Otherwise, the fuel which produce the least amount of particles emitted was $B P$ fuel. Although when this biofuel is used an increase in fresh air mass flow rate is observed, total particle concentration during the urban sections re- 
mains similar to $D .7 p p m$, producing a lower particle emission. In contrast, accumulation-mode particle concentration measurement during the last section the NEDC was lower, so it produces a lower particle emission level.

As final result, Figure 8 shows the different TPER index calculated for each fuel formulation. In this regard, the minimum value of TPER index is for D.7ppm, being the rest of fuel formulations above this value. The maximum value was found for BR fuel, which presents an increase around $18.05 \%$.

On the one hand, although D.50ppm presents both similar fuel consumption and LHV than D.7ppm, the increase in TPER index is around $13.8 \%$ due to the increase in total particles emitted as Figure 7 shows.

On the other hand, $B P$ fuel has the minimum value of particles emitted (Figure 7) but it presents higher TPER index referred to D.7ppm. The increase in TPER index is related to the decrease in LHV (Table 2) for this fuel formulation. In the case of $B R$ and $B S$ fuel, both presents higher fuel consumption and higher particle emission than D.7ppm fuel. Furthermore both also present less LHV, so it is expected an increase in TPER index.

Finally, for $F T$ fuel, fuel consumption was improved compared to $D .7 p p m$, but it presents an increase to $8 \%$ on particles emitted, being the increase in its LHV around 1.8\%, so it is confirmed the increase in particles emitted per energy unit.

\subsection{Particle size distribution analysis.}

In the next paragraphs the results of particle size distributions analysis are discussed. The results showed in Figure 9 and Figure 10 are represented in a three-dimensional graphics: particle number concentration $\left(\# / \mathrm{m}^{3}\right)$, particle size diameter (nm), and time evolution (s). The lines represented in the 3D surface correspond to 30, 50, 70, and 90 $\mathrm{nm}$ particle diameter. During the evolution of PSD, it can be distinguish two zones: a nucleation zone corresponding to particle size between 5.6 and $30 \mathrm{~nm}$, and accumulation zone, ranged from 30 to $560 \mathrm{~nm}$.

\subsubsection{Urban cycle (ECE-15).}

Figure 9 shows the results concerning to particle size distribution during the ECE-15. It can be noted that, as for particle emission analysis, this plots represent the average of the four subsequent ECE-15 cycles.

Plot A in Figure 9 represents the evolution of particle size distribution during the ECE-15 when D.7ppm fuel was used. In this case, most of particles emitted are in accumulation zone of PSD. The mode of these PSD varies along the ECE-15, being $80 \mathrm{~nm}$ during the first part of the cycle. In the second phase PSD-mode down to $70 \mathrm{~nm}$, moving to $60 \mathrm{~nm}$ in the last part of the cycle. When engine speed and load increase, mode shifts to smaller diameters and higher concentrations.

In the case of D.50ppm, plot B in Figure 9 depicts similar particle size distributions to a $D .7 p p m$ reference fuel. As a difference, a slight increase in accumulation-mode particle concentration in the last section of ECE-15 due to the sulfur content in the fuel is observed, acting this sulfur content as a precursor of particle formation.

When the analysis focuses on biodiesel fuels (Plots C, D and E in Figure 9), there is a reduction in PSD mode in all cases compared to the reference D.7ppm fuel. Furthermore, an increase in nucleation-mode particles and a new 
particle size distribution formation during idle phases occur. These phenomena are closely related to the deterioration in combustion process occuring at low load levels since the use of biofuels normally imply an ignition delay increase. Thus a higher peak heat release rate and more ringing than diesel at the same injection timing is expected [47].

At the final point, for $F T$ fuel case, Figure 9.F shows a reduction in PSDs mode refered to D.7ppm fuel reference. A reduction in accumulation-mode particles formation is expected caused by the absence of sulfur fuel content, the reduction in the hydrocarbon emission and the increase at DOC outlet temperature. In addition, particle size distributions measured with this fuel are in a narrower diameter range than biofuels.

\subsubsection{Extra Urban Driving Cycle (EUDC).}

Figure 10 displays particle size distributions during the EUDC phase for each different fuels used. For D.7ppm reference fuel (Plot A), a difference in terms of particle size spectrum respect to ECE-15 cycle is observed. In this case, particles below $30 \mathrm{~nm}$ almost disappeared. PSD-mode is located in $70 \mathrm{~nm}$ throughout the cycle, reaching maximum concentration peaks during acceleration ramp of 100 to $120 \mathrm{~km} / \mathrm{h}$.

Using D.50ppm fuel, particle size distribution are the same in terms of particle diameters range and PSD-mode. The difference resides in emission peak, around $8 \%$ higher than D.7ppm fuel $\left(1.65 \times 10^{13}\right.$ vs. $\left.1.8 \times 10^{13} \# / \mathrm{m}^{3}\right)$.

With the use of biofuels the trend for $B R, B S$ and $B P$ during EUDC (plot $\mathrm{C}$, plot $\mathrm{D}$ and plot $\mathrm{E}$ in Figure 10 respectively) is a reduction in PSD mode, as well as a shift in the range of diameters where in particles are emitted. Although maximum emission peaks with $B R$ fuel are below the peaks observed in the $D .7 p p m$ fuel, a remarkable increase in particles formation below $30 \mathrm{~nm}$ occurs. In this case, particles amount formed below $30 \mathrm{~nm}$ are contributing to this fuel with the highest particle emission depicted during the NEDC. In contrast, with the use of $B P$ fuel a reduction in diameters range, PSD mode and maximun emission peaks is observed. In addition, particle formation below $30 \mathrm{~nm}$ is lower than the other two biofuels. Thus, each sucess contribute to make the least particle emitted fuel, as previously Figure 7 shown.

At last, when the $F T$ fuel is used, particle size distribution are narrower and PSD-mode is increased, reaching values close to those obtained with $D .7 p p m$ fuel. Additionally, particle concentrations are even lower than $D .7 p p m$ fuel due to the decrease in fuel consumption observed with the use of this fuel.

\subsection{Geometric mean diamater analysis.}

The evolution of the geometric mean diameter in particle size distribution is another important parameter which provides information about particles emitted. It take into acount both the total quantity and particles concentration for each particle diameter, providing an overall evaluation of PSD.

In the case of ECE-15, Figure 11 shows the GMD evolution during this cycle. It can be seen that GMD for all fuels remains practically in the same range. Notably higher GMDs occur during deceleration zones (marked in Figure 11). This is due to the fuel injection cut-off that engine ECU provides during these zones. In this sense, nucleation-mode particles formation is closely related to the fuel injection, so these particles type are not present during the deceleration 
ramps. This behavior causes that GMD moves to a larger diameter since, although nucleation-mode particles are not formed, accumulation particles remaining in the exhaust line are dragged and emitted during these deceleration ramps.

In the case of the EUDC, the geometric mean diameter is kept in a stable accumulation range as shown Figure 12. The major variations occur in the area where the velocity is $50 \mathrm{~km} / \mathrm{h}$. In this sense, a decrease in GMD is observed when $B S$ and $B R$ fuels are used. It is due to the fact that nucleation-mode particles emitted during this strech are in major presence of than D.7ppm fuel, so GMD decrease as PSD moves to nucleation zones. In contrast, an increase in GMD is detected when $B P$ and $F T$ fuels are used due to the fact that particle mode concentration emitted are in accumulation zone (Figure 10.E and Figure 10.F), so an increase in GMD was expected.

When the analysis in this area was focused on D.50ppm, an increase in GMD respect to D.7ppm was found. In this sense, an increase in accumulation-mode particle concentration lies in a decrease in GMD.

\section{Summary and conclusions}

The experiments performed in this study have been carried out in a EURO 4 standards engine considering different biofuels and fischer tropsch fuel. The original D.7ppm fuel is considered as a reference being compared with the different fuels used. After present the most relevant conclusions on particle emission analysis, the main results of particle size distribution and geometric mean diameter during NEDC have been highlighted.

- Fuel consumption was improved for $F T$ fuel due to its lower heating value is higher than the D.7ppm fuel. For the biofuels case, an increase in fuel consumption was observed due to their lower heating values are less than the D.7ppm fuel.

- During the ECE-15 phase (low engine speed and load), accumulation-mode particle concentration are similar for all fuels excepting $B R$ fuel, which presents slightly higher. Contrary, several variations in accumulationmode particle concentration are found in the acceleration ramps of EUDC (medium engine speed and load).

- For ECE-15 phase, similar emission level in nucleation-mode particle concentration is depicted for all fuels tested. In contrast, an increase in this particle concentration at EUDC phase is observed with the use of biofuels.

- Through calculated "Total particle-energy ratio", all fuel formulations present higher TPER index than D.7ppm fuel. Specifically, for BR fuel, it presents the highest increase.

- A reduction in PSD mode during the assessment of ECE-15 is found for $B R, B S, B P$ and $F T$ fuels. Furthermore, for biofuels use $(B R, B S$ and $B P)$, a decrease in the range of accumulation-mode particles concentration referred to $D .7 p p m$ reference fuel is also depicted. In contrast, an increase in nucleation-mode particles formation is determined due to combustion deterioration at low speed and load for these fuels.

- A reduction in the range of particle diameter emitted and a decrease in accumulation particle mode concentration (PSD) with $F T$ fuel during the EUDC were found. 
- An increase in nucleation particles emission has been observed during the EUDC for $B R, B S$ and $B P$ fuels. For the D.50ppm fuel, the increase in PSD is noted for accumulation-mode particles.

- During the deceleration ramps in the whole cycle, all fuels show similar trend in GMD, being increased due to the absence of nucleation-mode particles presence. In general terms, for ECE-15 phase, GMDs remain at similar particle diameter independent of the fuel used. For EUDC case, a decrease in GMD is observed with $B S$ and $B R$ fuels. Contrarily, an increase with D.50ppm, FT, and $B P$ fuel were observed.

\section{Acknowledgements}

The equipment used in this work has been partially supported by FEDER project funds "Dotación de infraestructuras científico técnicas para el Centro Integral de Mejora Energética y Medioambiental de Sistemas de Transporte (CiMeT), (FEDER- ICTS-2012-06)", framed in the operational program of singular scientific and technical infrastructure of the Ministry of Science and Innovation of Spain.

\section{References}

[1] APHEIS (Air Pollution and Health: A European Information System) third year report 2004, Institut de Veille Sanitaire, Sant-Maurice European comission.

[2] F. Payri, J. M. Desantes (Eds.), Motores de combustión interna alternativos, Reverté (2011).

[3] R. B. Krieger, R. M. Siewert, J. A. Pinson, N. E. Gallopoulos et al., Diesel engines: One option to power future personal transportation vehicles, SAE Technical Paper 972683.

[4] E. Zervas, S. Poulopoulos, C. Philippopoulos, $\mathrm{CO}_{2}$ emissions change from the introduction of diesel passenger cars: case of greece, Energy 31(14) (2006) 2915-25.

[5] C. Arcoumanis, T. Kamimoto (Eds.), Flow and combustion in reciprocating engines, Springer, 2009.

[6] C. I. Davidson, R. F. Phalen, P. A. Solomon, Airborne particulate matter and human health: a review, Aerosol Science \& Technology 39(1) (2005) 62-78.

[7] C. Pope, D. Dockery, Health effects of fine particulate air pollution: lines that connect, Journal of the Air and Waste Management Association 56 (2006) 709-742.

[8] G. Oberdörster, M. J. Utell, Ultrafine particles in the urban air: to the respiratory track and beyond, Environmental Health Perspectives 110 (2002) A440-A441.

[9] The Council of The European Union 1999 Relating to limit values for sulfur dioxide, nitrogen dioxide and oxides of nitrogen, particulate matter and lead in ambient air, Council Directive 1999/30/EC of 22 April 1999 Official Journal of European Union L.163 (41) 4660

[10] B. Giechaskiel, P. Dilara, E. Sandbach, J. Andersson, Particle Measurement Programme (PMP) light-duty inter-laboratory exercise: comparison of different particle number measurement systems, Measurement Science and Technology 19 (2008) 095401.

[11] M. G. Khair, A review of diesel particulate filter technologies, SAE Technical Paper 2003-01-2303.

[12] J. Johnson, S. Bagley, L. Gratz, D. Leddy, A review of diesel particulate control technology and emissions effects, SAE Technical Paper 940233.

[13] J. Jang, Y. Lee, C. Cho, Y. Woo, C. Bae, Improvement of DME HCCI engine combustion by direct injection and EGR, Fuel 113 (2013) 617-624.

[14] A. K. Agarwal, D. K. Srivastava, A. Dhar, R. K. Maurya, P. C. Shukla, A. P. Singh, Effect of fuel injection timing and pressure on combustion, emissions and performance characteristics of a single cylinder diesel engine, Fuel 111 (2013) 374-383. 
[15] S. Park, Optimization of combustion chamber geometry and engine operating conditions for compression ignition engines fueled with dimethyl ether, Fuel 97 (2012) 61-71.

[16] V. Bermúdez, J. M. Luján, P. Piqueras, D. Campos, Pollutants emission and particle behavior in a pre-turbo aftertreatment light-duty diesel engine, Energy 66 (2014) 509-522.

[17] V. Bermúdez, J. M. Luján, B. Pla, W. G. Linares, Comparative study of regulated and unregulated gaseous emissions during nedc in a light-duty diesel engine fuel with Fischer Tropsch and biodiesel fuels, Biomass and Bioenergy 35 (2011) 789-798.

[18] L. Ryan, F. Convery, S. Ferreira, Stimulating the use of biofuels in the European Union: Implications for climate change policy, Energy Policy 34(17) (2006) 3184-3194.

[19] R. Morris, Y. Jia, Impact of biodiesel fuels on air quality and human health: task 5 report, Technical report, Air Toxics Modelling of the Effects of Biodiesel Fuel Use on Human Health in the South Coast Air Basin Region of Southern California National Renewable Energy Laboratory, Novato, CA (2003).

[20] K. Magara-Gómez, M. Olson, T. Okuda, K. Walz, J. Schauer, Sensitivity of hazardous air pollutant emissions to the combustion of blends of petroleum diesel and biodiesel fuel, Atmospheric Environment 50 (2012) 307-313.

[21] S. Pinzi, P. Rounce, J. M. Herreros, A. Tsolakis, M. P. Dorado, The effect of biodiesel fatty acid composition on combustion and diesel engine exhaust emissions, Fuel 104 (2013) 170-182.

[22] S. Puhan, N. Vedaraman, B. V. B. Ram, G. Sankarnarayanan, K. Jeychandran, Mahua oil (Madhuca Indica seed oil) methyl ester as biodieselpreparation and emission characteristics, Biomass and Bioenergy 28(1) (2005) 87-93.

[23] N. Usta, Use of tobacco seed oil methyl ester in a turbocharged indirect injection diesel engine, Biomass and Bioenergy 28(1) (2005) 77-86.

[24] H. Song, B. T. Tompkins, J. A. Bittle, T. J. Jacobs, Comparisons of NO emissions and soot concentrations from biodiesel-fuelled diesel engine, Fuel 96 (2012) 446-453.

[25] K. Bozbas, Biodiesel as an alternative motor fuel: Production and policies in the European Union, Renewable and Sustainable Energy Reviews 12(2) (2008) 542-552.

[26] A. J. Torregrosa, A. Broatch, B. Pla, L. F. Mónico, Impact of Fischer Tropsch and biodiesel fuels on trade-offs between pollutant emissions and combustion noise in diesel engines, Biomass and Bioenergy 52 (2013) 22-33.

[27] K. S. Ng, J. Sadhukhan, Techno-economic performance analysis of bio-oil based Fischer-Tropsch and CHP synthesis platform, Biomass and Bioenergy 35(7) (2011) 3218-3234

[28] D. Leckel, Diesel production from Fischer-Tropsch: the past, the present and new concepts, Energy fuels 23(5) (2009) 2342-2358.

[29] P. Schaberg, J. Botha, M. Schnell, H.-O. Hermann, N. Pelz, R. Maly, Emissions performance of GTL diesel fuel and blends with optimized engine calibrations, SAE Technical Paper 2005-01-2187.

[30] W. Hewu, H. Han, L. Xiha, Z. Ke, O. Minggao, Performance EURO III common rail heavy duty diesel engine fuelled with gas to liquid, Applied Energy 86 (2009) 2257-2261.

[31] O. Armas, R. García-Contreras, A. Ramos, Impact of alternative fuels on performance and pollutant emissions of a light duty engine tested under new european driving cycle, Applied Energy 107 (2013) 183-190.

[32] J. Zhang, K. He, X. Shi, Y. Zhao, Comparison of particle emissions from an engine operating on biodiesel and petroleum diesel, Fuel 90(6) (2011) 2089-2097.

[33] O. Armas, M. Lapuerta, A. Gómez, C. Mata, Effect of ethanol-diesel blends on the particle size distributions of a city bus,THIESEL: Conference of Thermo and Fluid Dynamic Processes in Diesel Engines (Valencia, September 2006) pp 421-432.

[34] H. Lee, Time-resolved particle emission and size distribution charachteristics during dynamic engine operation conditions with ethanolblended fuels, Fuel 88(9) (2009) 1680-1686.

[35] J. Galindo, V. Bermúdez, J. R. Serrano, J. J. López, Cycle to cycle diesel combustion characterization during engine transient operation, SAE Technical Paper 2001-01-3262.

[36] T. Johnson, R. Caldow, A. Pocher, A. Mirme, D. B. Kittelson, A new electrical mobility particle sizer spectrometer for engine exhaust particle measurements, SAE Technical Paper 2004-01-1341. 


\section{Nomenclature}

37] J. M. Desantes, V. Bermúdez, S. Molina, W. G. Linares, Methodology for measuring exhaust aerosol size distributions using an engine test under transient operating conditions, Measurement Science and Technology 22(11) (2011) 115101.

[38] Dekati Fine Smart Particle Sampler FPS-4000. User manual.

[39] D. Kim, M. Gautam, D. Gera, Parametric studies on the formation of diesel particulate matter via nucleation and coagulation modes, Journal of Aerosol Science 33(12) (2002) 1609-1621.

[40] I. S. Abdul-Khalek, D. B. Kittelson, B. R. Graskow, Q. Wei, F. Bear, Diesel exhaust particle size: measurement issues and trends, SAE International 980525 .

[41] W. C. Hinds (Ed.), Aerosol technology: Properties, behavior, and measurement of airborne particles, Wiley-Interscience, 1999.

[42] 2008/692/EC, Implementing and amending regulation (EC) n. 715/2007 of the European parliament and of the council on type-approval of motor vehicles with respect to emissions from light passenger and commercial vehicles (EURO 5 and EURO 6) and on access to vehicle repair and maintenance information.

[43] J. H. Seinfield, S. N. Pandis, Athmospheric Chemistry and Physics: From air pollution to climate change, 1998.

[44] M. Lapuerta, O. Armas, A. Gómez, Diesel particle size distribution estimation from digital image analysis, Aerosol Science and Technology 37(4) (2003) 369-381.

[45] A. Broatch, J. M. Luján, J. R. Serrano, B. Pla, Pollutants instantaneous measurement and data analysis of engine-in-the-loop tests, THIESEL: Conference of Thermo and Fluid Dynamic Processes in Diesel Engines (Valencia, September 2006) pp 197210.

[46] J. C. Stetter, D. E. Foster, J. J. Schauer, Modern diesel particulate matter measurements and the application of lessons learned to 2007 levels and beyond, SAE Technical Paper 2005-01-0194.

[47] J. Kim, J. Jang, K. Lee, Y. Lee, S. Oh, S. Lee, Combustion and emissions characteristics of diesel and soybean biodiesel over wide ranges of intake pressure and oxygen concentration in a compression ignition engine at a light-load condition, Fuel 129 (2014) 11-19.

Abbreviations

$\begin{array}{ll}\text { AFR } & \text { Air-to-fuel ratio } \\ B P & \text { BioPalm fuel } \\ B R & \text { BioRapeseed fuel } \\ B S & \text { BioSoybean fuel } \\ \text { D.7ppm } & 7 \text { ppm sulfur content diesel } \\ \text { D.50ppm } & 50 \text { ppm sulfur content diesel } \\ \text { DOC } & \text { Diesel oxidation catalyst } \\ \text { DR } & \text { Dilution ratio } \\ \text { DPF } & \text { Diesel particulate filter } \\ \text { ECE-15 } & \text { Urban driving cycle } \\ \text { ECU } & \text { Electronic control unit } \\ \text { ED } & \text { Ejector diluter } \\ \text { EEPS } & \text { Engine exhaust particle sizer } \\ \text { EUDC } & \text { Extra urban driving cycle }\end{array}$




$\begin{array}{ll}\text { FPS } & \text { Fine particle sampler } \\ \text { FT } & \text { Fischer Tropsch fuel } \\ \text { GMD } & \text { Geometric mean diameter } \\ \text { GTL } & \text { Gas to liquid fuel process } \\ \text { HP-EGR } & \text { High pressure exhaust gas recirculation } \\ \text { HSDI } & \text { High speed direct injection } \\ \text { LSD } & \text { Low sulfur diesel } \\ \text { NEDC } & \text { New european driving cycle } \\ \text { PTD } & \text { Porous tube diluter } \\ \text { PSD } & \text { Particle size distribution } \\ \text { SOF } & \text { Soluble organic fraction } \\ \text { TPER } & \text { Total particle-energy ratio } \\ \text { ULSD } & \text { Ultra low sulfur diesel }\end{array}$

\section{List of Tables}

- Table 1.- Engine main characteristics.

- Table 2.- Fuel properties.

\section{List of Figures}

- Figure 1.- Experimental setup for particle emission evaluation during NEDC.

- Figure 2.- Particle evolution at dilution system. Theoretical phase-diagram used in the methodology for measuring particle distribution size [37].

- Figure 3.- Test procedure for testing each fuel formulation.

- Figure 4.- Fuel consumption during NEDC with different fuels formulation.

- Figure 5.- Air mass flow rate during NEDC with different fuels formulation.

- Figure 6.- Particle emission evaluation during NEDC. A) Total particle concentration during ECE-15 with different fuels. B) Total particle concentration during EUDC with different fuels. C) Accumulation particle concentration during ECE-15 with different fuels. D) Accumulation particle concentration during EUDC with different fuels. E) Nucleation particle concentration during ECE-15 with different fuels. F) Nucleation particle concentration during EUDC with different fuels.

- Figure 7.- Total particle emitted during NEDC with different fuels.

- Figure 8. "Total particle-energy ratio"

- Figure 9.- Particle size distribution during ECE-15 with different fuels. A) D.7ppm fuel. B) D.50ppm. C) $B R$ fuel. D) $B S$ fuel. E) $B P$ fuel. F) $F T$ fuel.

- Figure 10.- Particle size distribution during EUDC with different fuels. A) D.7ppm fuel. B) D.50ppm. C) $B R$ fuel. D) $B S$ fuel. E) $B P$ fuel. F) $F T$ fuel. 
- Figure 11.- Geometric mean diamater evaluation during ECE-15 with different fuels.

- Figure 12.- Geometric mean diamater evaluation during EUDC with different fuels. 
Table 1: Engine main characteristics.

\begin{tabular}{ll}
\hline \hline Type & 4-cycle \\
Displacement & $1998\left[\mathrm{~cm}^{3}\right]$ \\
Diameter & $85[\mathrm{~mm}]$ \\
Stroke & $88[\mathrm{~mm}]$ \\
Number of cylinders & $4[-]$ \\
Valves per cilinder & $4[-]$ \\
Compression ratio & $18: 1[-]$ \\
Maximun power & $100[\mathrm{~kW}]$ at $4000 \mathrm{rpm}$ \\
Maximun torque & $320[\mathrm{~N} \cdot \mathrm{m}]$ at $1750 \mathrm{rpm}$ \\
\hline \hline
\end{tabular}

Table 2: Fuels properties.

\begin{tabular}{|c|c|c|c|c|c|c|c|}
\hline Property & Unit & $D .7 p p m^{(a)}$ & $D .50 p p m$ (b) & $B P^{(\mathrm{c})}$ & $B S^{(\mathrm{d})}$ & $B R^{(\mathrm{e})}$ & $F T^{(\mathrm{f})}$ \\
\hline Summarized formula & {$[-]$} & $\mathrm{C}_{14.3} \mathrm{H}_{26.6}$ & $\mathrm{C}_{15.2} \mathrm{H}_{27.3}$ & $\mathrm{C}_{17.8} \mathrm{H}_{34.5} \mathrm{O}_{2}$ & $\mathrm{C}_{18.2} \mathrm{H}_{33.4} \mathrm{O}_{2}$ & $\mathrm{C}_{18.3} \mathrm{H}_{34} \mathrm{O}_{2}$ & $\mathrm{C}_{14.1} \mathrm{H}_{30}$ \\
\hline Cetane number & {$[-]$} & 50.5 & 51.5 & $69.5^{(*)}$ & 50.6 & 56.6 & $81.2^{(*)}$ \\
\hline Viscosity at $40^{\circ} \mathrm{C}$ & {$\left[\mathrm{mm}^{2} / \mathrm{s}\right]$} & 2.68 & 2.85 & 4.44 & 4.24 & 4.68 & 2.79 \\
\hline Density at $15^{\circ} \mathrm{C}$ & {$[\mathrm{kg} / \mathrm{L}]$} & 0.84 & 0.84 & 0.87 & 0.88 & 0.88 & 0.77 \\
\hline Lower heating value & {$[\mathrm{MJ} / \mathrm{kg}]$} & 42.9 & 42.8 & 36.6 & 36.8 & 37.1 & 43.7 \\
\hline Sulfur content & {$[\mathrm{mg} / \mathrm{kg}]$} & 7.4 & 27.9 & 1.9 & 2.8 & 1.7 & 0.4 \\
\hline Oxygen content & {$[\%(\mathrm{~m} / \mathrm{m})]$} & 0 & 0 & 11.4 & 11.2 & 11.3 & 0 \\
\hline Stoichiometric air-fuel ratio & {$[-]$} & 14.66 & 14.43 & 12.6 & 12.49 & 12.54 & 15.04 \\
\hline Distillation $10 \%$ vol. & {$\left[{ }^{\circ} \mathrm{C}\right]$} & 195 & 198 & 314 & 316 & 323 & 212 \\
\hline Distillation $50 \%$ vol. & {$\left[{ }^{\circ} \mathrm{C}\right]$} & 262 & 274 & 323 & 328 & 332 & 271 \\
\hline Distillation $90 \%$ vol. & {$\left[{ }^{\circ} \mathrm{C}\right]$} & 339 & 357 & 330 & 334 & 342 & 344 \\
\hline Oxidation stability at $100^{\circ} \mathrm{C}$ & {$[\mathrm{h}]$} & $>72$ & $>72$ & 9.2 & 9.6 & 6.2 & 55.2 \\
\hline
\end{tabular}




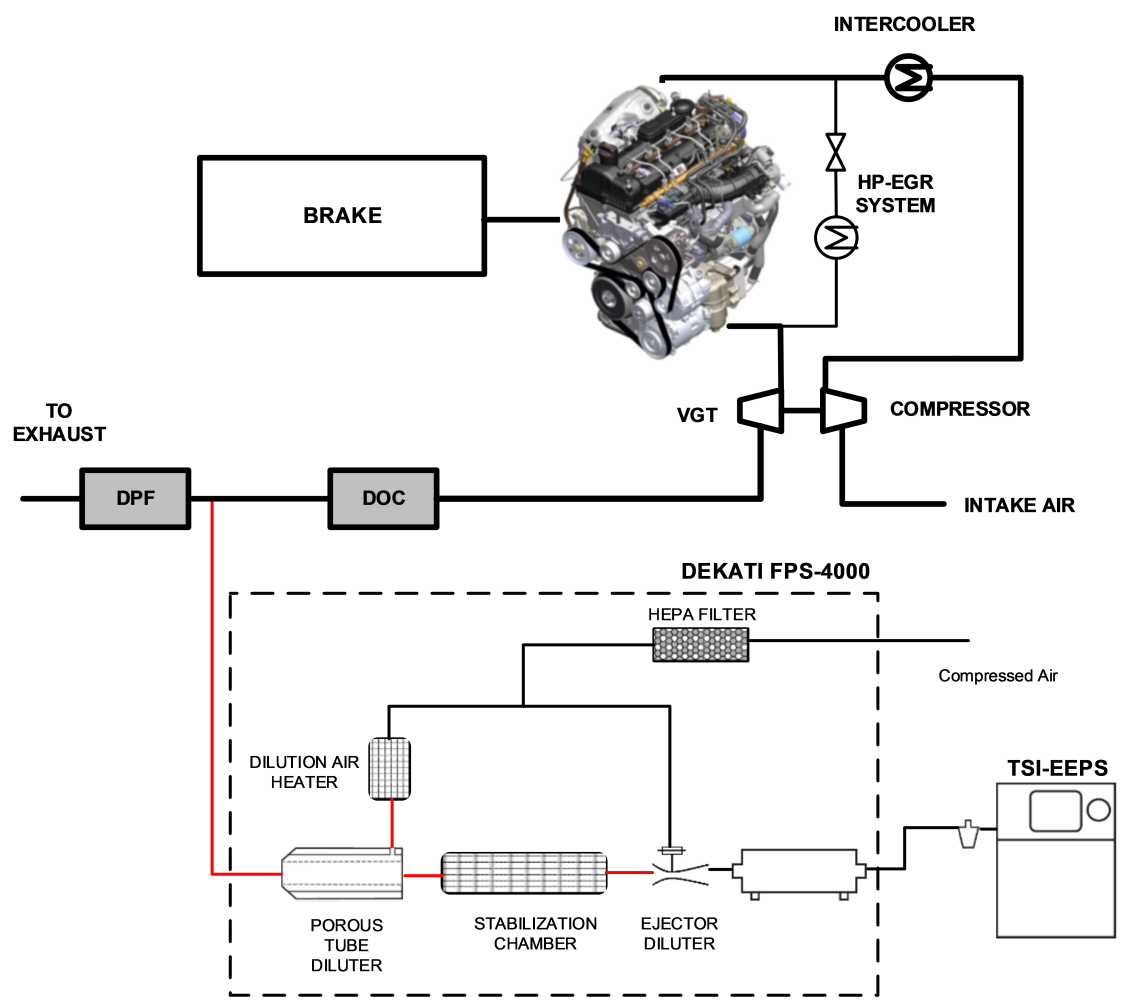

Figure 1: Experimental setup for particle emission evaluation during NEDC.

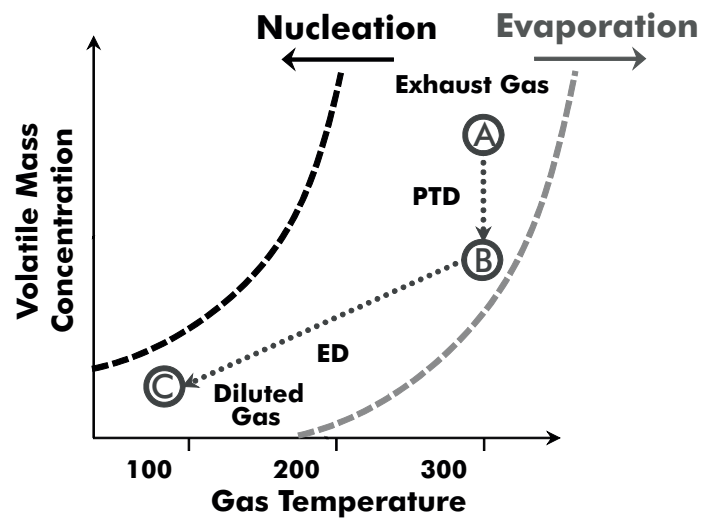

Figure 2: Particle evolution at dilution system. Theoretical phase-diagram used in the methodology for measuring particle distribution size [37]. 


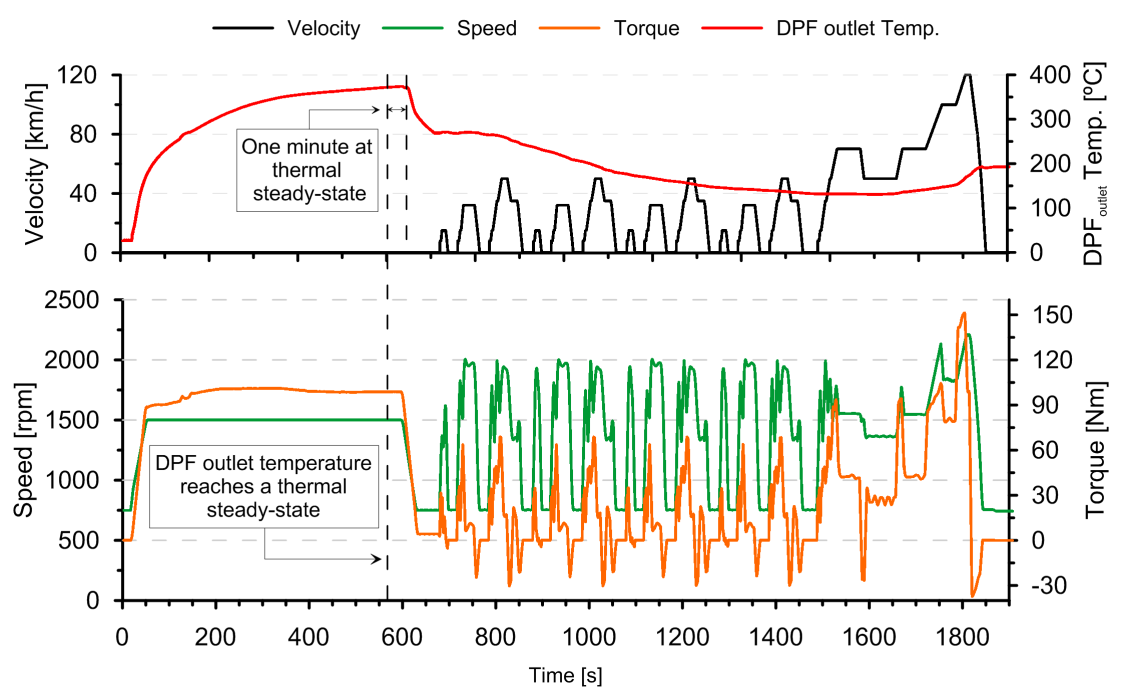

Figure 3: Test procedure for testing each fuel formulation.

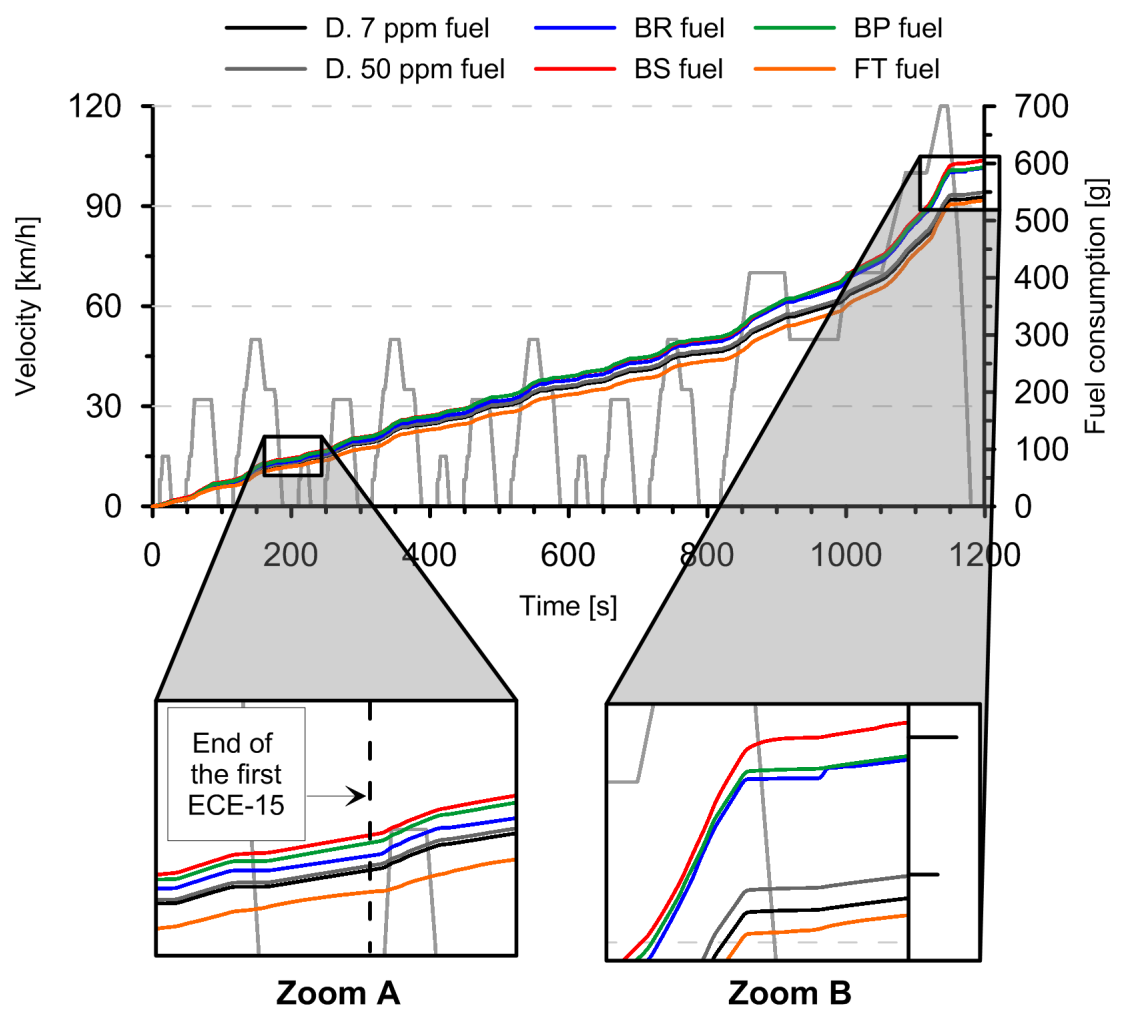

Figure 4: Fuel consumption during NEDC with differenet fuels formulation. 


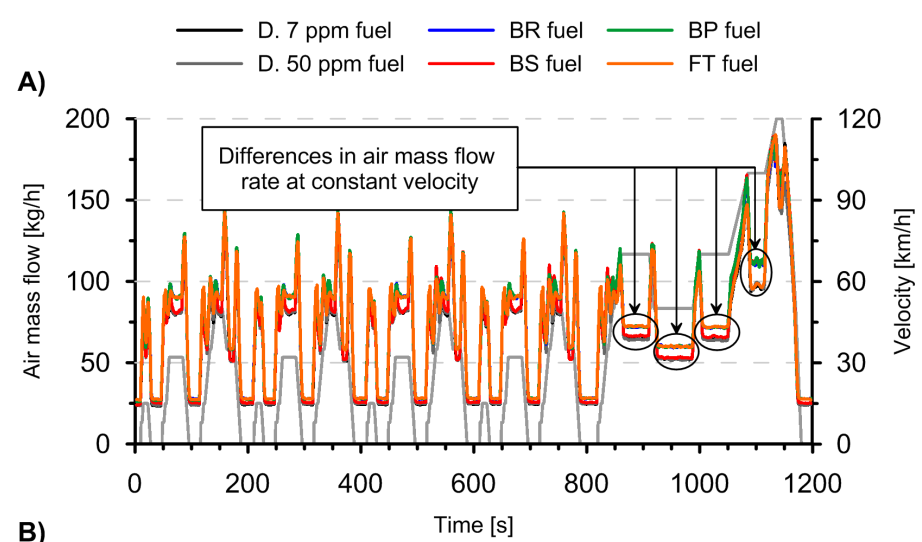

B)

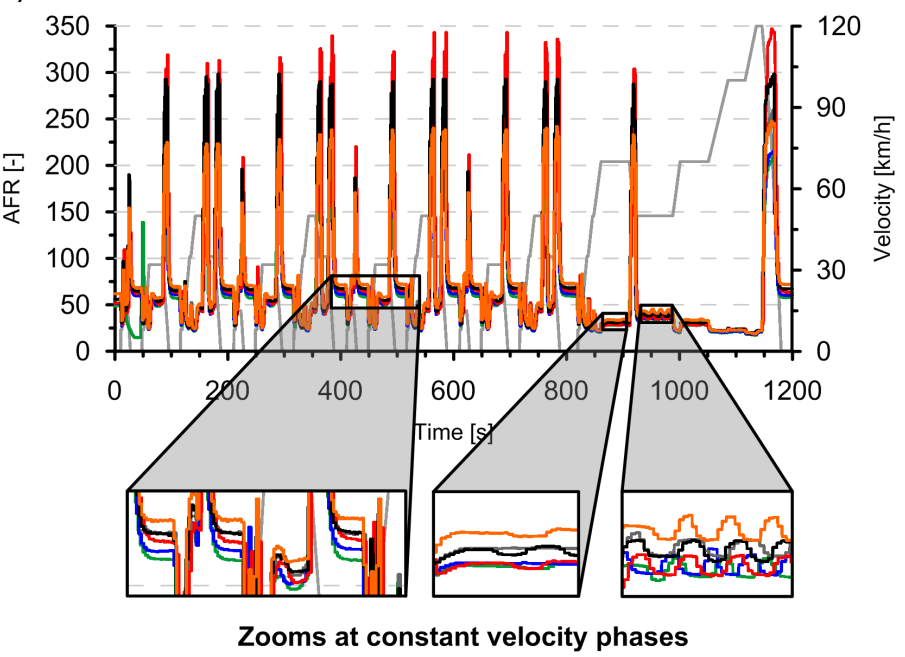

Figure 5: Air mass flow rate during NEDC with different fuels formulation. 

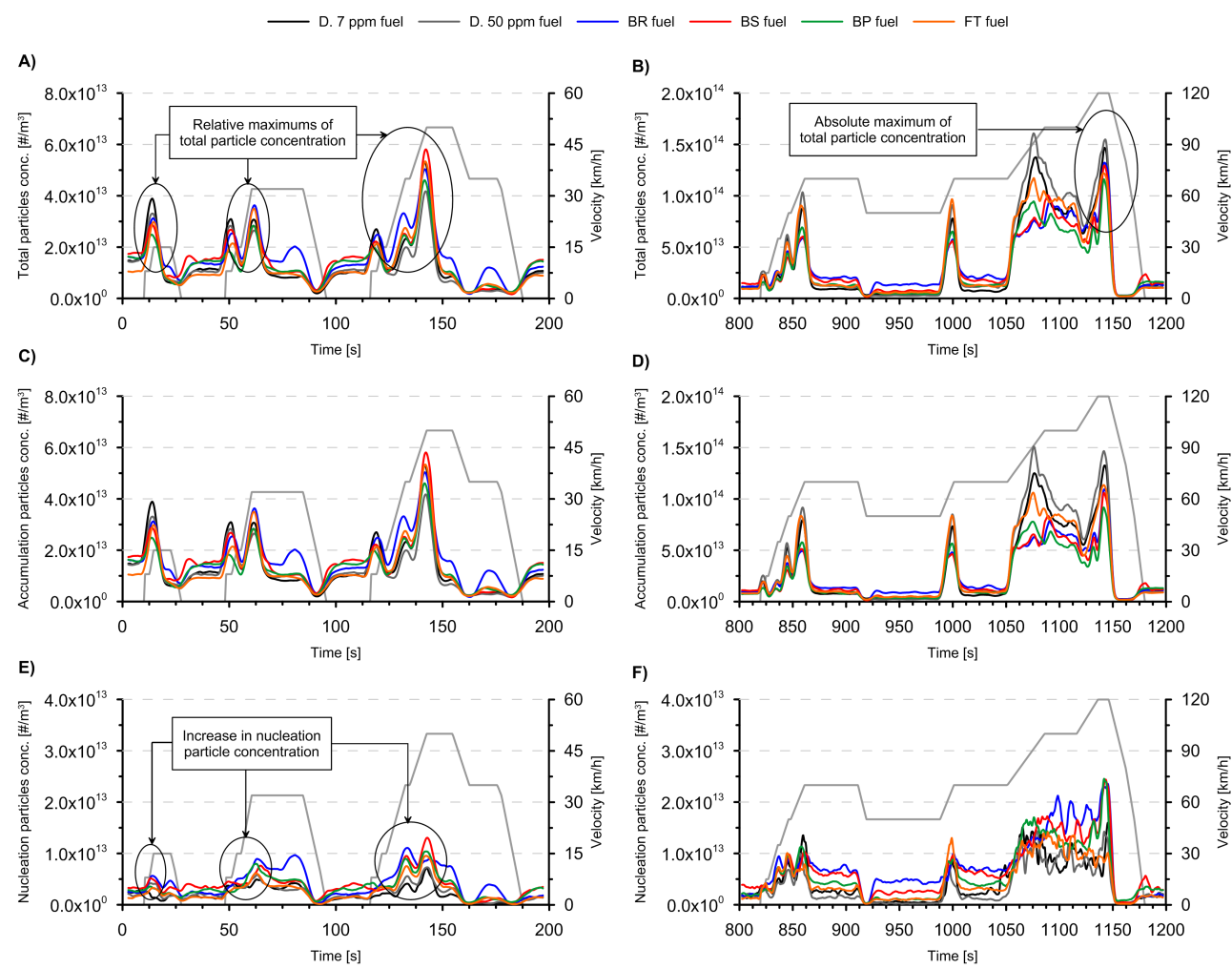

Figure 6: Particle emission evaluation during NEDC. A) Total particle concentration during ECE-15 with different fuels. B) Total particle concentration during EUDC with different fuels. C) Accumulation particle concentration during ECE-15 with different fuels. D) Accumulation particle concentration during EUDC with different fuels. E) Nucleation particle concentration during ECE-15 with different fuels. F) Nucleation particle concentration during EUDC with different fuels.

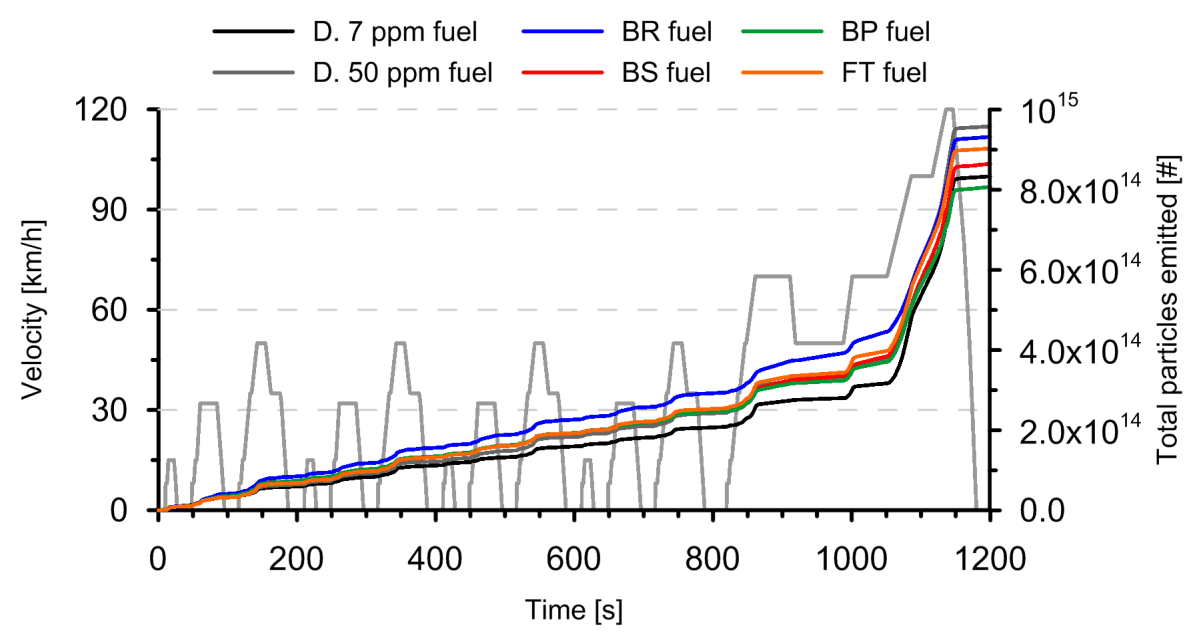

Figure 7: Total particle emitted during NEDC with different fuels. 


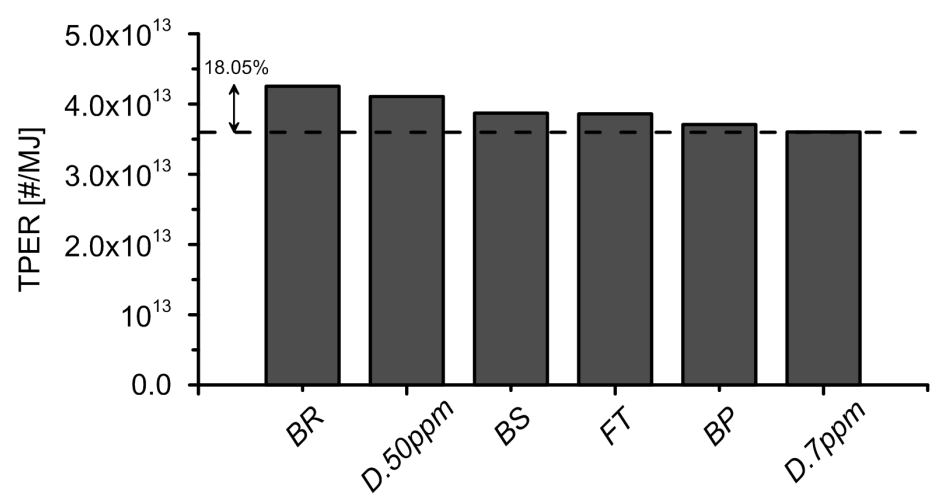

Figure 8: “Total particle-energy ratio". 

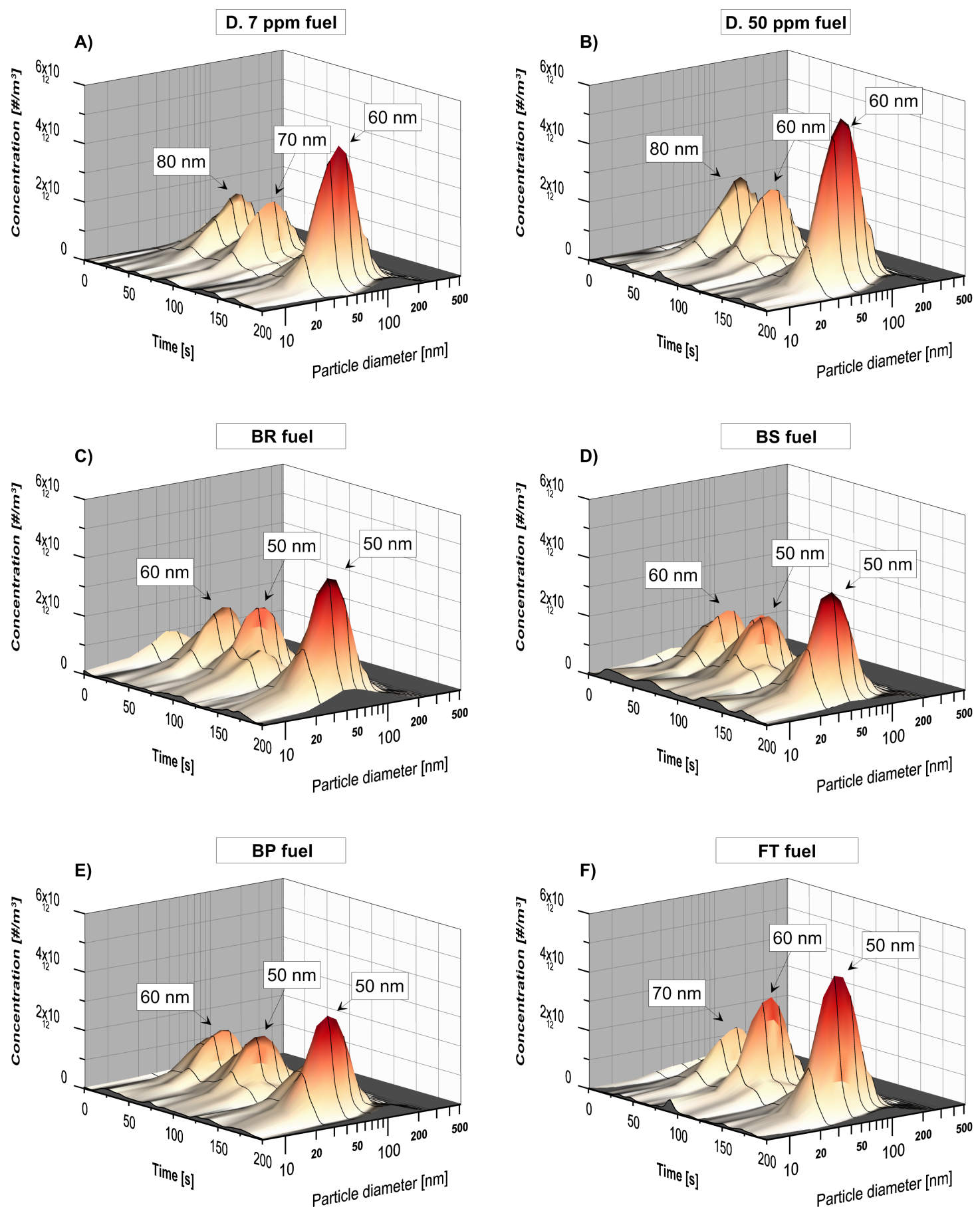

Figure 9: Particle size distribution during ECE-15 with different fuels. A) $D .7 p p m$ fuel. B) $D .50 p p m$ fuel. C) $B R$ fuel. D) $B S$ fuel. E) $B P$ fuel. F) $F T$ fuel. 

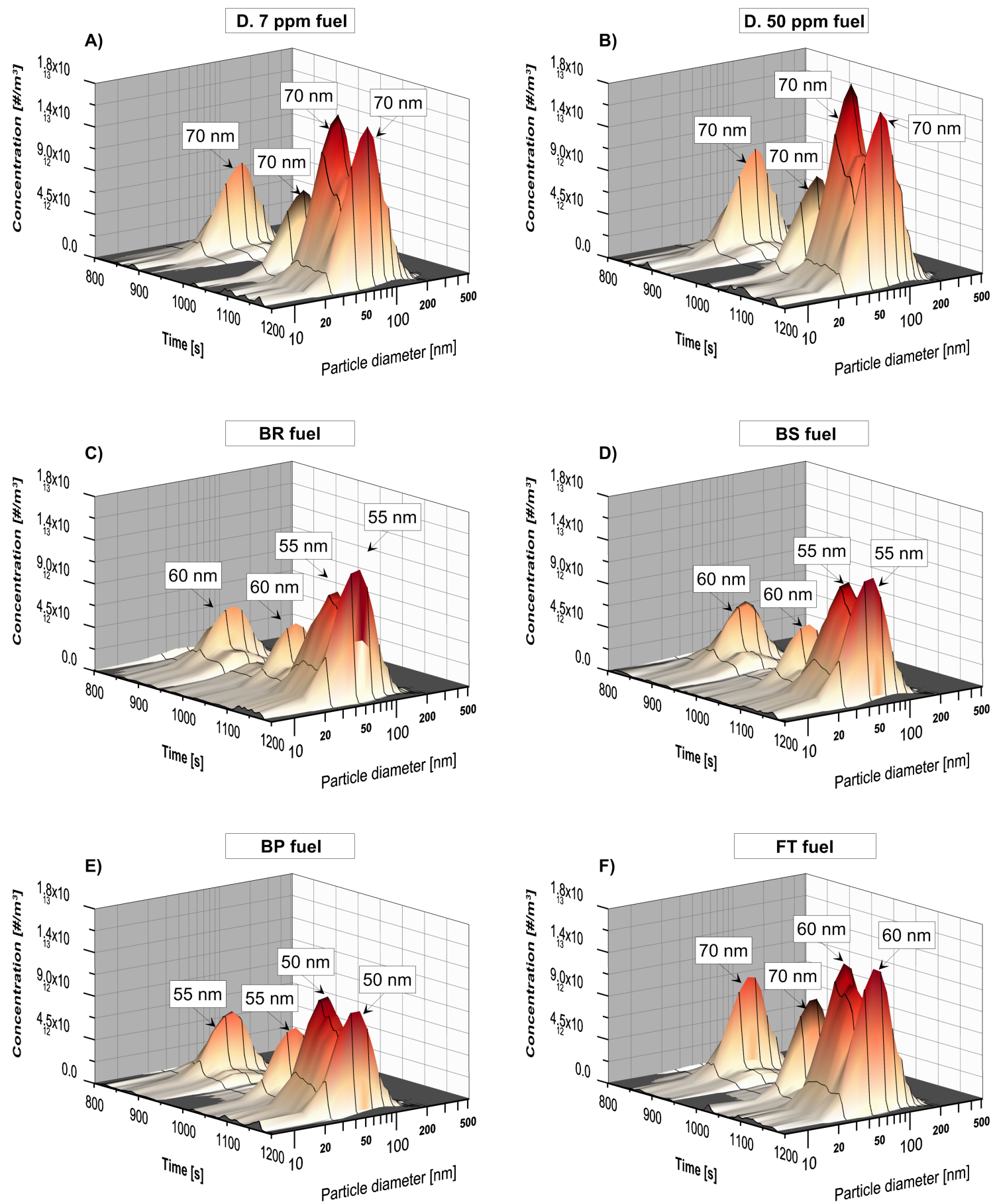

Figure 10: Particle size distribution during EUDC with different fuels. A) D.7ppm fuel. B) D.50ppm fuel. C) $B R$ fuel. D) $B S$ fuel. E) $B P$ fuel. F) FT fuel. 


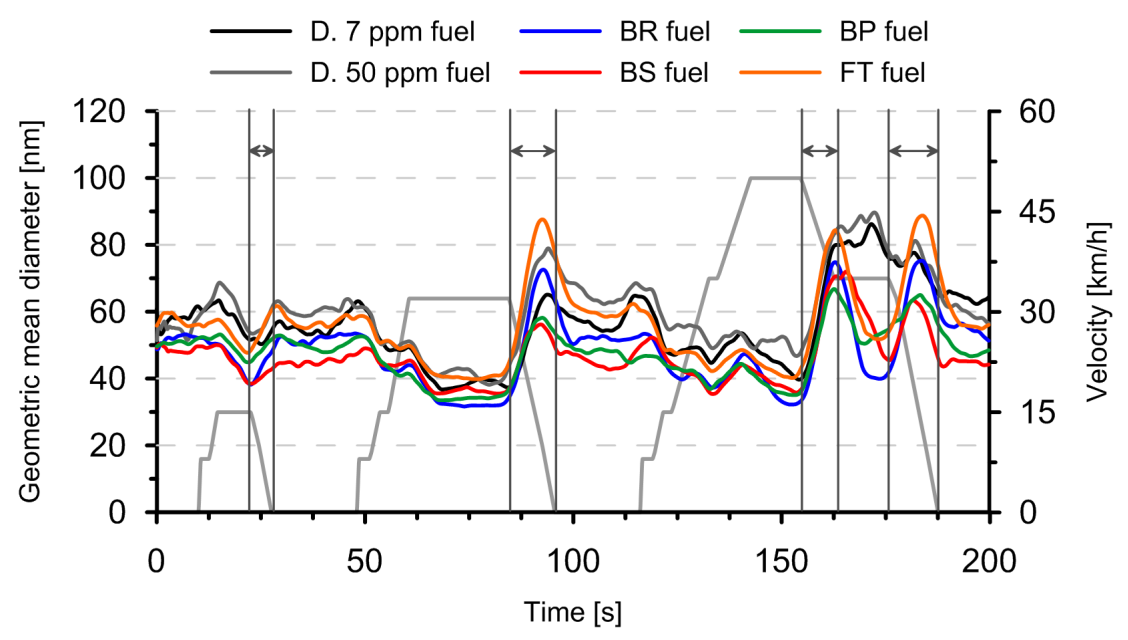

Figure 11: Geometric mean diamater evaluation during ECE-15 with different fuels.

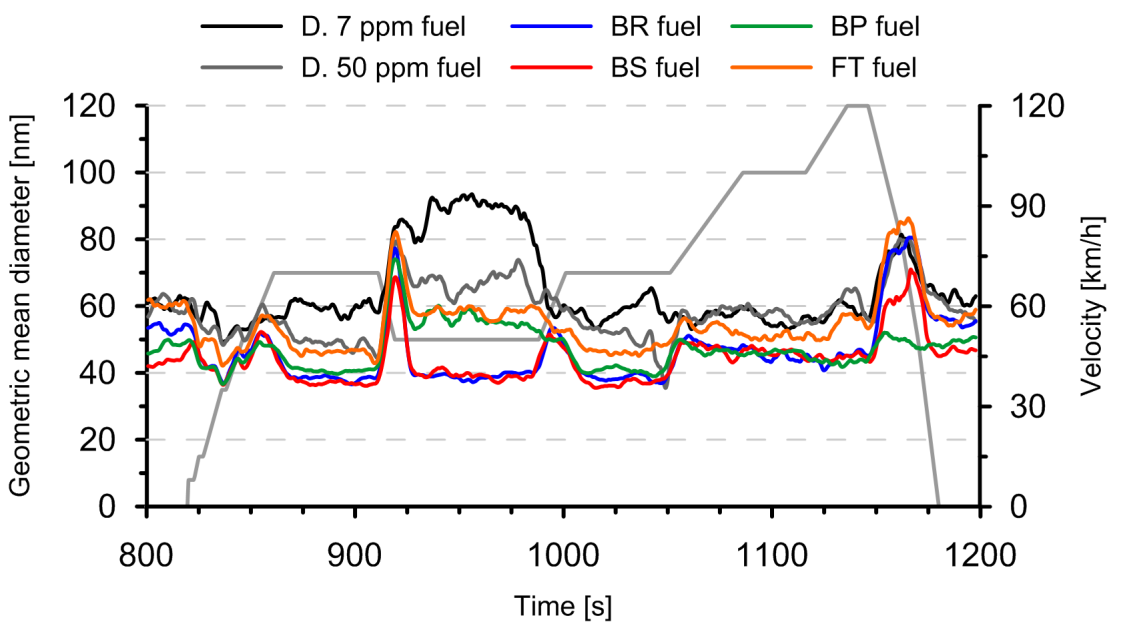

Figure 12: Geometric mean diamater evaluation during EUDC with different fuels. 